\title{
Experimental Study on Emission Characteristics during Combustion of Single Bamboo Pellet
}

\author{
Haobin Peng ${ }^{1}$, Guohua Chen ${ }^{1, *}$, Yuesheng $\mathrm{Li}^{2}$, Zhiming Jiang ${ }^{2}$, Mengquan $\mathrm{Yu}^{2}$ and Yunquan $\mathrm{Li}^{2}$ \\ ${ }^{1}$ School of Mechanical and Automotive Engineering, South China University of Technology, 510640 Guangzhou, China \\ ${ }^{2}$ Shunde Detection, Special Equipment Inspection Institute of Guangdong Province, 528300 Shunde, China
}

\begin{abstract}
Some specific bamboo pellets were combusted in a tube furnace individually in different constant air flow rates (3,4 and $5 \mathrm{~L} / \mathrm{min})$ and at various temperatures $\left(800,900,1000,1100\right.$ and $\left.1200^{\circ} \mathrm{C}\right)$, in order to investigate the dynamic emission characteristics during various respective combustion processes. The results indicate that the increase of carbon monoxide(CO) amounts in $3 \mathrm{~L} / \mathrm{min}$ air flow rate was caused by kinetic controlled combustion at $800{ }^{\circ} \mathrm{C}$ and by diffusion controlled combustion at 1100 and $1200{ }^{\circ} \mathrm{C}$. The yield and concentration of nitric oxide(NO) reach the maximums at $900{ }^{\circ} \mathrm{C}$, as well as the conversion rate from fuel-N to $\mathrm{NO}(9.17 \%)$. As combustion temperature increases, the yield and concentration of NO decline from the peak, and the conversion rate (from fuel-N to NO) falls to the lowest value (3.90\%) at $1200{ }^{\circ} \mathrm{C}$ in $3 \mathrm{~L} / \mathrm{min}$ air flow rate. When a bamboo pellet burns sufficiently almost none sulfur dioxide $\left(\mathrm{SO}_{2}\right)$ was released, while the $\mathrm{S}$ element can be kept in the ash or discharged in high-temperature flue gas in the form of sulfate which is converted from fuel-S. In oxy-lean atmosphere, $\mathrm{SO}_{2}$ generates from the decomposition or oxidation of organic $\mathrm{S}$ during early devolatilisation, wheares more fuel-S probably are released in the forms of $\mathrm{H}_{2} \mathrm{~S}$ and $\mathrm{CaS}$.
\end{abstract}

\section{Introduction}

With the depletion of conventional energy sources and the environmental damages by overuse of fossil fuels, biomass pellet fuel has been widely used in heating and power generation because of its extensive sources, renewable specific, $\mathrm{CO}_{2}$ neutrality, and mature utilization ways to use, etc. ${ }^{[1]}$. However, the detrimental emissions of $\mathrm{CO}, \mathrm{NO}$ and $\mathrm{SO}_{2}$ during combustion cannot be ignored in large-scale application. Experts and scholars have carried out many thorough researches about biomass combustion and the accompanied emissions ${ }^{[2,3]}$. At present, the researches on the characteristics of biomass pellets combustion are mainly focus on two aspects: one is based on the small sample of micro particles ${ }^{[4-8]}$, avoiding the influence of internal heat and mass transfer in combustion process; the other is macro research based on pack-bed combustion ${ }^{[9-13]}$, which focuses on the characteristics of flue gas emissions in the case of the coupling of chemical and physical factors during overall combustion. It is worth pointing out that the biomass pellet structure has a direct impact on the emission characteristics of combustion products ${ }^{[14,15]}$, and the internal heat and mass transfer processes also have important influences on the pyrolysis and combustion products ${ }^{[16]}$.

In conclusion, the characteristics of single pellets in combustion cannot be completely presented in combustion tests of either fine particles or pack-bed pellets. In addition, the current investigation on flue gas emission characteristics during biomass pellet combustion mainly concentrates in the low temperature regions $\left(\leq 1000{ }^{\circ} \mathrm{C}\right)^{[15,16]}$, while the generation rules at high temperatures are still lack of research. Based on the single bamboo pellet, the emission characteristics of harmful components in flue gas, such as $\mathrm{CO}, \mathrm{NO}$ and $\mathrm{SO}_{2}$, were studied under the conditions of different oxygen contents and temperatures, in order to provide references for the efficient and clean utilization of bamboo residues.

\section{Materials and methods}

\subsection{Apparatus}

Figure 1 shows the schematic diagram of the testing system for combustion experiments in this paper. The principle part is a temperature programming furnace reactor, with a horizontal tube of $60 \mathrm{~mm}$ inner diameter and $300 \mathrm{~mm}$ effective heating length at the center. The furnace is heated by Si-Mo heating elements, allowing the highest operation temperature to reach up to $1550{ }^{\circ} \mathrm{C}$. The tests were conducted in various air flow rates $(3,4$ and $5 \mathrm{~L} / \mathrm{min})$ and temperatures $(800,900,1000,1100$ and $1200{ }^{\circ} \mathrm{C}$ ), respectively. A bamboo pellet carried by an alundum crucible was rapidly put into the center of the reactor with stable pre-set temperature and air flow rate. The flue gas produced by combustion of the bamboo pellet was sampled at the rear end of the reactor for a gas analyser typed VARIO plus Industry which recorded the concentrations of the uncondensable gas such as $\mathrm{O}_{2}, \mathrm{CO}$, $\mathrm{NO}$ and $\mathrm{SO}_{2}$ every $2 \mathrm{~s}$.

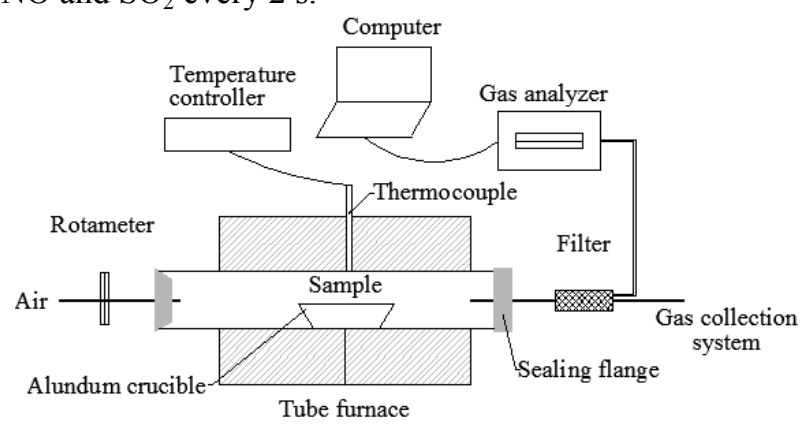

Figure 1 Schematic illustration of the reactor.

\subsection{Materials}

The raw materials including the residues of branches, leaves, sawdust, etc. was provided by a bamboo 
processing mill located in Zhaoqing city, Guangdong province. The raw materials were crushed and extruded into densified pellets with diameters of approximately 8 $\mathrm{mm}$ and length of 40-60 $\mathrm{mm}$. To ensure the representativeness, all samples were collected from one batch in dispersive spots. The compositions and element analysis results of the samples are listed in Table 1 . The shape of the pellets under tests is shown in Figure 2, and the weight is around $1000 \mathrm{mg}$.

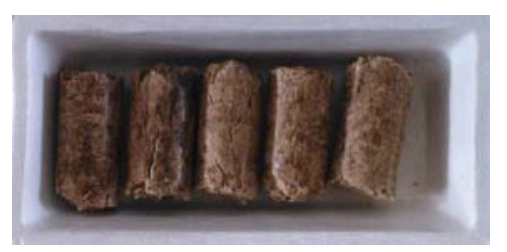

Figure 2 Bamboo pellet samples.

Table 1 Proximate and ultimate analysis of bamboo pellet.

\begin{tabular}{|c|c|c|c|c|}
\hline \multicolumn{4}{|c|}{ Proximate analysis / \% } & \multirow{2}{*}{$\begin{array}{l}\mathbf{L H V}_{\mathrm{ad}} \\
/ \mathbf{M J} \cdot \mathbf{k g}^{-1}\end{array}$} \\
\hline $\mathbf{M}_{\mathrm{ad}}$ & $\mathbf{V}_{\text {ad }}$ & $\mathbf{A}_{\mathrm{ad}}$ & $\mathbf{F C}_{\mathrm{ad}}$ & \\
\hline 9.73 & 69.09 & 4.65 & 16.53 & 16.12 \\
\hline \multicolumn{5}{|c|}{ Ultimate analysis / \% } \\
\hline $\mathbf{C}_{\text {daf }}$ & $\mathbf{H}_{\text {daf }}$ & $\mathbf{O}_{\text {daf }}$ & $\mathbf{N}_{\text {daf }}$ & $S_{\text {daf }}$ \\
\hline 41.04 & 5.99 & 37.49 & 1.01 & 0.09 \\
\hline
\end{tabular}

\subsection{Calculation methodology}

The yields of $\mathrm{CO}, \mathrm{NO}, \mathrm{SO}_{2}$ in flue gas were estimated by integration of the respective concentration curves as per Eq. (1):

$$
\begin{aligned}
& N_{i}=\sum_{j=1}^{k} c_{j} \times 10^{-6} \times v_{I} / 60 \times 1000 \times t \times M_{i} / 22.4 \\
& i: \mathrm{CO}, \mathrm{NO}, \mathrm{SO}_{2} \quad v_{I}=3,4,5
\end{aligned}
$$

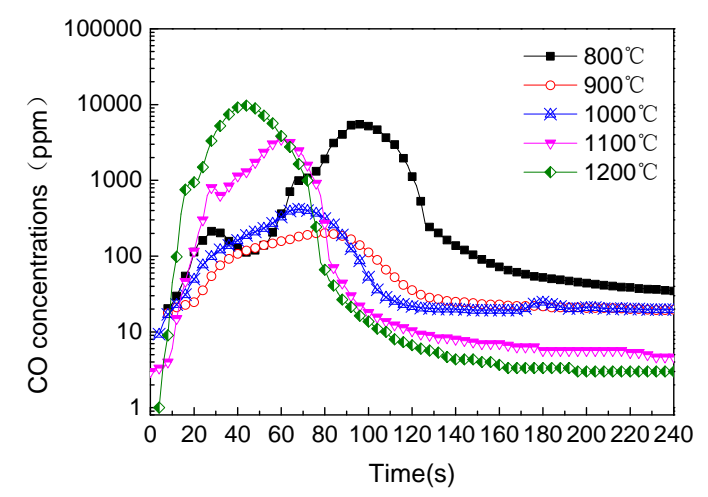

(a) where $N_{i}$ is the total yield of one substance $(\mathrm{mg}), c_{j}$ is volume concentration at actual time $\left(10^{-6}\right), v_{I}$ is the air flow rate $(\mathrm{L} / \mathrm{min}), M_{i}$ is the molecular weight $(\mathrm{g} / \mathrm{mol}), t$ is sampling time interval(s), $k$ is the number of sampling points.

The conversion rates of fuel $\mathrm{N}$ and $\mathrm{S}$ were estimated by the emission amounts of $\mathrm{NO}$ and $\mathrm{SO}_{2}$ :

$$
X_{i}=\frac{N_{i} \times A_{r} \times n / M_{i}}{m \times N_{d}} \times 100 \% \quad i: \mathrm{N}, \mathrm{S}
$$

where $X_{i}$ is conversion $\operatorname{rate}(\%), A_{r}$ is relative atomic weight, $n$ is the number of a certain element in a gas molecule; $m$ is the mass of fuel sample $(\mathrm{mg}), N_{d}$ is the mass fraction of a certain element in fuel $(\%)$.

\section{Results and discussion}

\subsection{CO emissions}

In Figure $3 \mathrm{a} \sim 3 \mathrm{~d}$ the variations of $\mathrm{CO}$ emission concentrations and yields are shown during bamboo pellet combustion under different temperatures and air flow rates. The $\mathrm{CO}$ concentration in flue gas directly reflects the actual combustion condition, and can be used to determine the interaction extent between volatile and other combustion products during pyrolysis and combustion.

Figure $3 \mathrm{a} \sim \mathrm{c}$ show that the $\mathrm{CO}$ emission peaks narrow down with the increasing combustion temperature. It's because higher temperature leads to higher combustion rate, and hence the time required from the beginning of devolatilisation to the end of char combustion is shortened. For this reason, a bamboo pellet has better combustion characteristics at higher temperature.

Figure $3 \mathrm{~d}$ shows that the yield of $\mathrm{CO}$ at $800{ }^{\circ} \mathrm{C}$ is much higher than other temperatures except $1200{ }^{\circ} \mathrm{C}$. The

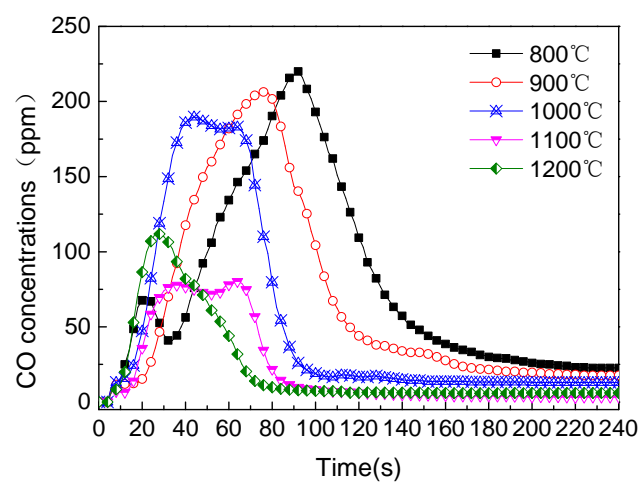

(b) 


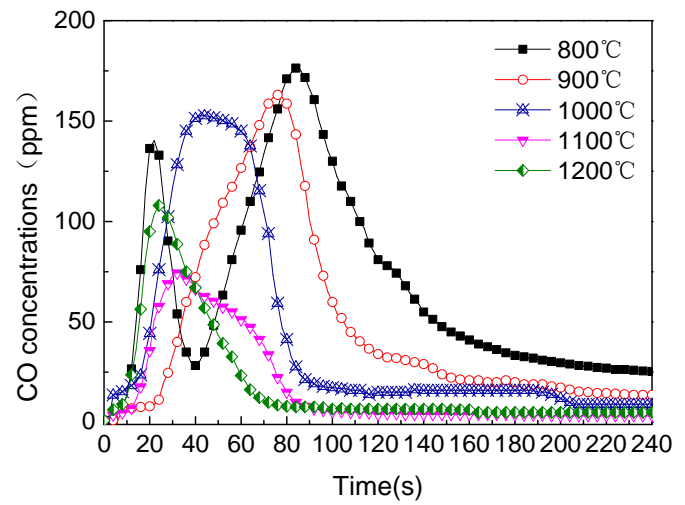

(c) $\mathrm{L} / \mathrm{min}$ air flow, (c) $5 \mathrm{~L} / \mathrm{min}$ air flow. (d) $\mathrm{CO}$ yields at different combustion temperatures and air flows.

combustion may be in kinetic controlled at $800{ }^{\circ} \mathrm{C}$, with higher devolatilisation rate than combustion rate, leading to a large amount of $\mathrm{CO}$ generation under the oxy-lean atmosphere. As the temperature rises, the combustion rate on the pellet surface exceeds the devolatilisation rate, and the combustion turns gradually into diffusion controlled in which the global combustion rate depends on the diffusion rate of oxygen from environment to particle surface. Therefore, to strengthen the combustion of bamboo pellet, sufficient oxygen supply capacity should be ensured in addition to combustion temperature increment.

During the combustion in $3 \mathrm{~L} / \mathrm{min}$ air flow rate, the peaks of CO concentration curves at $1100{ }^{\circ} \mathrm{C}$ and $1200{ }^{\circ} \mathrm{C}$ are much higher than the peaks at $900{ }^{\circ} \mathrm{C}$ and $1000{ }^{\circ} \mathrm{C}$, while it is contrary in $4,5 \mathrm{~L} / \mathrm{min}$ air flow rate. The former is due to the large instantaneous consumption of $\mathrm{O}_{2}$ caused by the rapid devolatilisation at high temperature(as shown in Figure 4), so the emission concentrations and yields of $\mathrm{CO}$ increase significantly under oxy-lean atmosphere. Moreover, NO generates in larger amount at high temperatures, thereby to reduce more generating $\mathrm{CO}$ and decrease both of its concentration and yield.

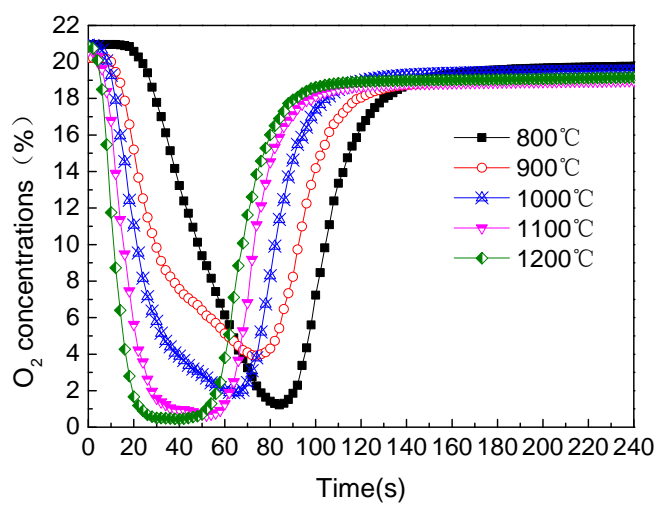

Figure $4 \mathrm{O}_{2}$ concentrations in $3 \mathrm{~L} / \mathrm{min}$ air flow.

\subsection{NO emissions}

The highest temperature of the biomass pack-bed combustion is generally not more than $1300{ }^{\circ} \mathrm{C}^{[17]}$ at

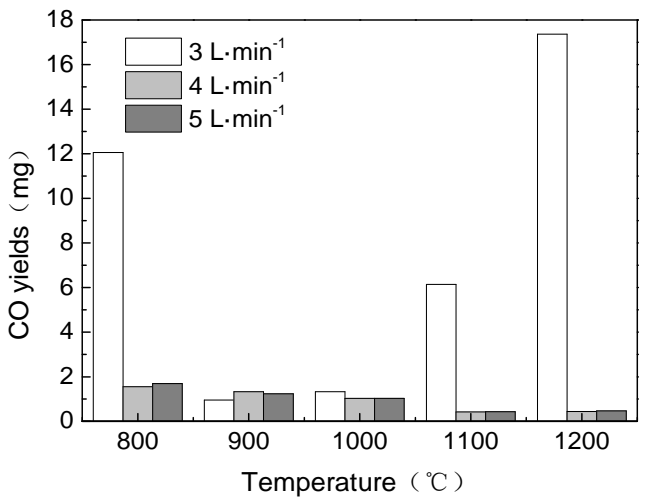

which NO emissions account for more than $90 \%$ of total $\mathrm{NO}_{\mathrm{x}}$ and most of the NO consists of fuel-NO, the rest such as thermal-NO and prompt-NO can be ignored. Therefore, the characteristics of fuel-NO emission are analyzed emphatically in this paper. Under the test conditions of this paper, most of the fuel-N comes from volatile-N whereas seldom from char- $\mathrm{N}^{[18]}$. Fuel-N mainly transfers to $\mathrm{NO}$ precursors $\left(\mathrm{HCN}, \mathrm{NH}_{3}\right.$ and $\mathrm{HNCO}$ ) in the form of volatile-N during combustion. The precursors can transfer to $\mathrm{NO}$ or $\mathrm{N}_{2}$ in reduction or oxidation atmosphere respectively, whereas char- $\mathrm{N}$ is oxidized to NO primarily.

Figure $5 \mathrm{a}$ shows that in air flow rate of $3 \mathrm{~L} / \mathrm{min}$, the NO concentration peaks in flue gas differ largely at various temperatures, e.g. the highest peak appears at $900{ }^{\circ} \mathrm{C}$, the following lower peak at $1000{ }^{\circ} \mathrm{C}$. During devolatilisation, the largest proportion of component in volatile- $\mathrm{N}$ is $\mathrm{NH}_{3}$, while the slightly lesser one is $\mathrm{HCN}^{[19]}$. However, NO productions are directly affected by the changes of $\mathrm{NH}_{3}$ and $\mathrm{HCN}$ in the volatile with various combustion temperatures. The changing rules of $\mathrm{NH}_{3}$ and $\mathrm{HCN}$ in volatile with combustion temperature variation are relevant to the $\mathrm{NO}$ production. Above $900{ }^{\circ} \mathrm{C}$, the $\mathrm{NH}_{3}$ formation rates are stable or abate slightly ${ }^{[20]}$, and the concentrations of NO reach the maximum. Moreover, large amount of $\mathrm{CO}$ generate during combustion at $800^{\circ} \mathrm{C}$, $900{ }^{\circ} \mathrm{C}$, and $1200{ }^{\circ} \mathrm{C}$, forming oxy-lean atmosphere under which hardly can $\mathrm{NH}_{3}$ and $\mathrm{HCN}$ transform to $\mathrm{NO}$ by reaction with $\mathrm{O}_{2}$, additionally more $\mathrm{NO}$ are reduced to $\mathrm{N}_{2}$.

Figure $5 \mathrm{~b}$ and $\mathrm{c}$ show that the shapes of $\mathrm{NO}$ concentration curves at different temperatures in air flow rate of 4 and $5 \mathrm{~L} / \mathrm{min}$ are similar, i.e. the characteristics of NO production and emission are stable at various temperatures in oxy-abundant atmosphere. Whereas in air flow rate of $3 \mathrm{~L} / \mathrm{min}$, NO concentration curves became complicate within the relative oxy-lean atmosphere. At relatively high temperatures $\left(1100\right.$ and $\left.1200{ }^{\circ} \mathrm{C}\right)$ and in oxy-lean atmosphere $(3 \mathrm{~L} / \mathrm{min}$ air flow rate), the bamboo pellet is burned incompletely to form large amounts of $\mathrm{CO}$ accompanying with hydrocarbon, e.g. $\mathrm{CH}_{4}$ and $\mathrm{SO}_{2}$. All of these intermediate products react with fuel-N intricately, making the generation mechanism of $\mathrm{NO}$ more complicated. 


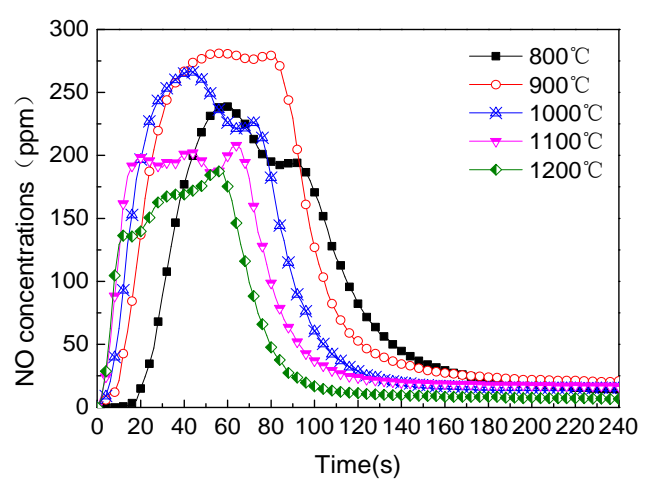

(a)

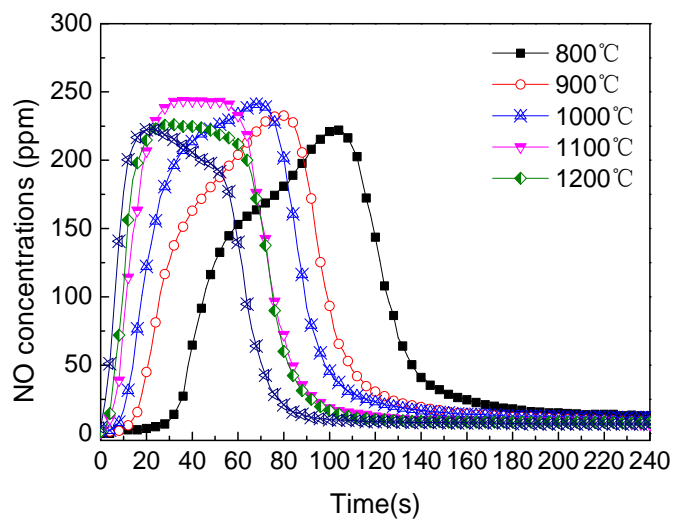

(c)

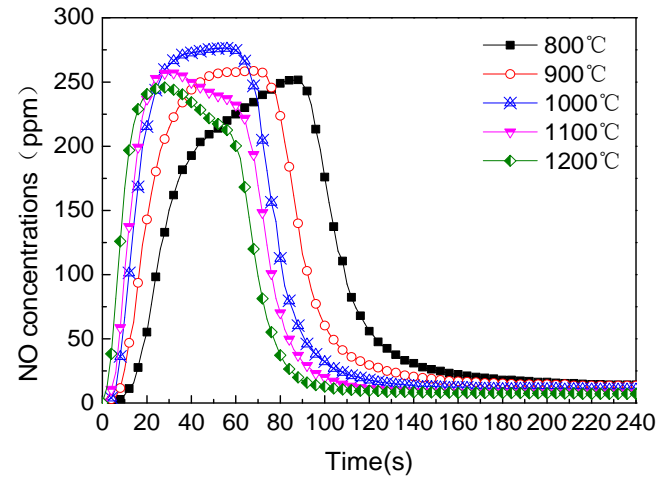

(b)

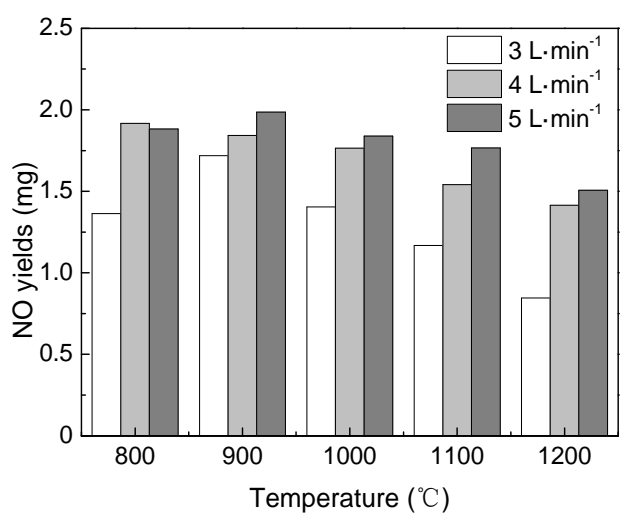

(d)

Figure 5 NO concentrations and yields at different combustion temperature and air flow. NO concentrations in: (a) 3 L/min air flow, (b) $4 \mathrm{~L} / \mathrm{min}$ air flow, (c) $5 \mathrm{~L} / \mathrm{min}$ air flow. (d) NO yields at different combustion temperatures and air flows.

Figure $5 \mathrm{~d}$ shows the yield properties of $\mathrm{NO}$ in various atmospheres and at different temperatures. In oxyabundant atmosphere, NO emission level reaches the maximum at $900{ }^{\circ} \mathrm{C}$, consistent with Tian et al. ${ }^{[20]}$. Above $900{ }^{\circ} \mathrm{C}$, the $\mathrm{NO}$ yields and fuel-N conversion rates can be reduced by decreasing the air supply (Table 2). Therefore, the NO yield during bamboo pellet combustion can be reduced effectively by burning in oxylean atmosphere.

Table 2 Fuel-N conversion rates at different combustion temperatures and air flows.

\begin{tabular}{|c|c|c|c|c|c|}
\hline \multirow{2}{*}{$\begin{array}{c}\text { Air flow/ } \\
\text { L· } \mathbf{m i n}^{-1}\end{array}$} & \multicolumn{5}{|c|}{ Conversion rate/ \% } \\
\cline { 2 - 6 } & $\mathbf{8 0 0}{ }^{\circ} \mathrm{C}$ & $\mathbf{9 0 0}{ }^{\circ} \mathrm{C}$ & $\mathbf{1 0 0 0}^{\circ} \mathrm{C}$ & $\mathbf{1 1 0 0}{ }^{\circ} \mathrm{C}$ & $\mathbf{1 2 0 0}{ }^{\circ} \mathrm{C}$ \\
\hline 3 & 6.30 & 7.93 & 6.48 & 5.39 & 3.90 \\
\hline 4 & 8.85 & 8.51 & 8.15 & 7.12 & 6.53 \\
\hline 5 & 8.70 & 9.17 & 8.49 & 8.15 & 6.96 \\
\hline
\end{tabular}

\section{$3.3 \mathrm{SO}_{2}$ emissions}

During bamboo pellet combustion, the $\mathrm{S}$ element is released in forms of $\mathrm{H}_{2} \mathrm{~S}$ and $\mathrm{SO}_{2}$ in gas phase mostly. The sulfur compounds are mainly produced by the decomposition of organic $\mathrm{S}$ compounds with poor heat stability or inorganic sulfate in volatile combustion stage and char combustion stage respectively ${ }^{[21]}$.
Figure 6 shows that $\mathrm{SO}_{2}$ can only be detected in $3 \mathrm{~L}$ $/ \mathrm{min}$ air flow rate at 800,1100 and $1200{ }^{\circ} \mathrm{C}$. It can be concluded that sulfur compounds can be absorbed by the matrix of char ${ }^{[21]}$ at relatively lower temperature and in oxy-abundant atmosphere during combustion, but the absorption capacity of char matrix will reduce at relatively higher temperature, leading to more $\mathrm{SO}_{2}$ oxidized from element $\mathrm{S}$ released, which can subsequently react with alkali compounds to form stable inorganic sulfate(chemical formula (3)) in solid phase ${ }^{[22]}$. In Figure $3 \mathrm{a} \sim 3 \mathrm{c}$, we can find that nearly no $\mathrm{SO}_{2}$ generates during sufficient burning.

$$
\mathrm{SO}_{2}(\mathrm{~g})+1 / 2 \mathrm{O}_{2}(\mathrm{~g})+\mathrm{H}_{2} \mathrm{O}(\mathrm{g})+2 \mathrm{KCl}(\mathrm{g}) \rightarrow \mathrm{K}_{2} \mathrm{SO}_{4}(\mathrm{~g})+2 \mathrm{HCl}(\mathrm{g})
$$

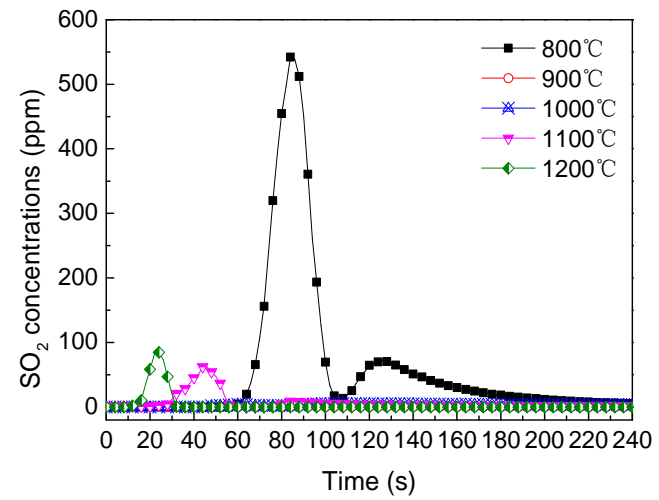

Figure $6 \mathrm{SO}_{2}$ concentrations in $3 \mathrm{~L} / \mathrm{min}$ air. 
As mentioned before, the combustion is in kinetic controlled under strong reduction atmosphere, thus in air flow rate of $3 \mathrm{~L} / \mathrm{min}$ and at combustion temperature of $800{ }^{\circ} \mathrm{C}$, against the reaction according to formula (3) that $\mathrm{SO}_{2}$ can release with flue gas, while the concentration curve is similar to $\mathrm{CO}$ under the same condition (Figure $3 a)$. With the deepening of char combustion, the sulfates detained in the char matrix will decompose in strong reducing atmosphere ( formula (4)) to release a small amount of $\mathrm{SO}_{2}$, forming the second peak of $\mathrm{SO}_{2}$ concentration curve(Figure 6). At 1100 and $1200{ }^{\circ} \mathrm{C}, \mathrm{SO}_{2}$ is released with flue gas, yet isn't converted into sulfate as the $\mathrm{SO}_{2}$ will be difficult to react with alkali compounds (formula (3)) while the pellet is burnt in oxy-lean atmosphere(Figure 3a). The rest of the S-containing compounds in gas phase mainly are discharged in forms of $\mathrm{H}_{2} \mathrm{~S}$ and $\mathrm{CaS}^{[15]}$.

$$
\mathrm{K}_{2} \mathrm{SO}_{4}(\mathrm{~s})+\mathrm{CO}(\mathrm{g}) \rightarrow \mathrm{K}_{2} \mathrm{CO}_{3}(\mathrm{~s})+\mathrm{SO}_{2}(\mathrm{~g})
$$

\section{Conclusions}

Combustion of an individual bamboo pellet is in chemical kinetic controlled at $800{ }^{\circ} \mathrm{C}$ that the rate of devolatilisation is much larger than pellet-surface combustion. The peaks of $\mathrm{CO}$ concentration curves narrow down as the combustion temperature increases in the air flow rate of 4 and $5 \mathrm{~L} / \mathrm{min}$, shortening the time from the beginning of devolatilisation to the end of char combustion.

Both the peaks of concentration and total yields of $\mathrm{NO}$ in flue gas reach their maximum values at $900{ }^{\circ} \mathrm{C}$, and the conversion rate from fuel-N to $\mathrm{NO}$ is no more than $9.17 \%$, i.e. the highest proportion recorded in tests. With increasing combustion temperature and enhancing reduction atmosphere, some of the released NO are reduced and the NO emission level is declined, while only $3.90 \%$ of fuel-N is transferred into NO in air flow rate of $3 \mathrm{~L} / \mathrm{min}$ at $1200{ }^{\circ} \mathrm{C}$. The lowest conversion rate is recorded in tests.

Almost no $\mathrm{SO}_{2}$ is released with flue gas in full combustion because the fuel-S is primarily transferred to sulfate detained in the ash. However, $\mathrm{SO}_{2}$ can be detected in flue gas during incomplete combustion, which is mainly produced from decomposition and oxidation of organic S during devolitilisation, as only a small part from decomposition of inorganic $\mathrm{S}$ in char combustion stage. Additionally in reduction atmosphere, some of the element $\mathrm{S}$ release in the forms of $\mathrm{H}_{2} \mathrm{~S}$ and $\mathrm{CaS}$.

\section{Acknowledgments}

This work was financially supported by Chinese Ministry of Education and Ministry of Science and Technology, who sponsored the Industry-AcademiaResearch Programme of Guangdong province (project No.2012B091000156).

\section{References}

[1] S. Bram, J. De Ruyck, D. Lavric. Applied Energy 2,
86 (2009) 194-201.

[2] H. Haberl, D. Sprinz, M. Bonazountas, P. Cocco, Y. Desaubies, M. Henze, O. Hertel, R.K. Johnson, U. Kastrup, P. Laconte, E. Lange, P. Novak, J. Paavola, A. Reenberg, S. van den Hove, T. Vermeire, P. Wadhams, T. Searchinger. Energy Policy, 45 (2012) 18-23.

[3] J. Tissari, K. Hytönen, O. Sippula, J. Jokiniemi. Biomass and Bioenergy 3, 33 (2009) 513-520.

[4] J. Bai, C. Yu, L. Li, P. Wu, Z. Luo, M. Ni. Energy \& Fuels 1, 27 (2013) 515-522.

[5] F.S. Akinrinola, L.I. Darvell, J.M. Jones, A. Williams, J.A. Fuwape. Energy \& Fuels 6, 28 (2014) 3821-3832.

[6] P. Brassard, J.H. Palacios, S. Godbout, D. Bussières, R. Lagacé, J. Larouche, F. Pelletier. Bioresource Technology, 155 (2014) 300-306.

[7] Q. Ren, C. Zhao, L. Duan, X. Chen. Bioresource Technology 14, 102 (2011) 7211-7217.

[8] C. Ndibe, J. Maier, G. Scheffknecht. Biomass and Bioenergy, 79 (2015) 105-115.

[9] J.P. Carroll, J.M. Finnan, F. Biedermann, T. Brunner, I. Obernberger. Fuel, 155 (2015) 37-43.

[10] A.H. Mahmoudi, M. Markovic, B. Peters, G. Brem. Fuel, 150 (2015) 573-582.

[11] M. Buchmayr, J. Gruber, M. Hargassner, C. Hochenauer. Biomass and Bioenergy, 81 (2015) 356-363. [12] M. Gehrig, S. Pelz, D. Jaeger, G. Hofmeister, A. Groll, H. Thorwarth, W. Haslinger. Applied Energy, 159 (2015) 310-316.

[13] M.M. Roy \& K.W. Corscadden. Applied Energy, 99 (2012) 206-212.

[14] E. Houshfar, Ø. Skreiberg, T. Løvås, D. Todorović, L. Sørum. Energy \& Fuels 10, 25 (2011) 4643-4654.

[15] J.N. Knudsen, P.A. Jensen, W. Lin, F.J. Frandsen, K. Dam-Johansen. Energy \& Fuels 3, 18 (2004) 810-819.

[16] M. Díaz-Ramírez, F.J. Frandsen, P. Glarborg, F. Sebastián, J. Royo. Fuel, 134 (2014) 209-219.

[17] H. Sefidari, N. Razmjoo, M. Strand. Fuel, 135 (2014) 120-129.

[18] P. Glarborg. Progress in Energy and Combustion Science 2, 29 (2003) 89-113.

[19] M. Becidan, Ø. Skreiberg, J.E. Hustad. Energy \& Fuels 2, 21 (2007) 1173-1180.

[20] F. TIAN, J. YU, L. MCKENZIE, J. HAYASHI, T. CHIBA, C. LI. Fuel 4, 84 (2005) 371-376.

[21] S.C. van Lith, V. Alonso-Ramírez, P.A. Jensen, F.J. Frandsen, P. Glarborg. Energy \& Fuels 3, 20 (2006) 964978.

[22] L. Hindiyarti, F. Frandsen, H. Livbjerg, P. Glarborg, P. Marshall. Fuel 8-9, 87 (2008) 1591-1600. 